\title{
A NOVEL MICROBIAL FUEL CELL TECHNOLOGY FOR ENERGY GENERATION AND COMPARISON OF POWER DENSITIES FOR DIFFERENT ELECTRODES USING NANOTECHNOLOGY
}

\author{
Samatha Singh" and S. Suresh \\ Chemical Engineering Department, Biochemical and Bioenergy Engineering Research \\ Laboratory, MANIT, Bhopal, 462003, M.P. India \\ "E-mail: samathakumbham@gmail.com
}

\begin{abstract}
For the world to prosper water and energy place an important role, in this research article focus is on producing energy from wastewater, it solves two problems. One of the most promising technologies is the Microbial Fuel Cell (MFC). The major drawback of this MFC is low power density; to get suitable electrode material three MFCs are compared for generating energy in terms of power density, those are Iron, Copper and, Silver nanoparticles(SNP) coated copper electrodes and experiments were conducted with Khan river wastewater as substrate. The major reason to use silver nanoparticles is promising antibacterial properties. Results were compared and found that copper electrodes have given maximum power density of $49.158172 \mu \mathrm{W} / \mathrm{mm}^{2}$ and COD, BOD is reduced to about $80 \%$.

Keywords: Electrodes, Microbial Fuel Cell(MFC), Power Density, Silver Nanoparticles (SNP)
\end{abstract}

(C) RASĀYAN. All rights reserved

\section{INTRODUCTION}

As recently developed technologies, Biotechnologies and Biological chemistry are producing innovative changes to acquire a better ecosystem, less pollution, biodegradable materials development and environmentally safe waste disposable with new production processes of renewable energy. ${ }^{1}$ Microorganisms can channel the electrons to the electrodes and they are converting the energy into methane, hydrogen, and electricity. Throughout the last decade, fossil fuels are mostly influenced by industrial and economic growth. ${ }^{2-3}$ Nevertheless, fossil fuels may not be the only deciding factor of global economic growth; they are also dangerous to the environment and human health. When these readily available energy sources are diminished due to heavy dependency for energy, the world will suffer energy scarcity for upcoming years. Hence, the only practical solution for this problem is the generation of renewable energy without pollutants as bi-products. ${ }^{4}$

Microbial Fuel cell (MFC) is a novel technology that is developed to generate electricity and to reduce BOD and COD from wastewater. ${ }^{5}$ This technology provides dual benefits by directly converting wastewater organic matter into energy through the oxidation process and has a wide potential and economical interest in wastewater treatment field. ${ }^{6-7}$ Over the past few decades, Nanotechnology has been developed as one of the important technical areas in various industries like wastewater treatment, food, and medicines. Collaborating nanomaterials with MFC will improve electricity generation. Synthesization of Nanoparticles can be done using various green and cost-effective methods such as green synthesis, nanoprecipitation technique and sol-gel method. ${ }^{8-10}$ Nanoparticles can improve the power extraction by exploiting biogenic inorganic nanoparticles to facilitate extracellular electron transfer in MFCs. ${ }^{10}$

\section{Components of MFCs}

\section{EXPERIMENTAL}

Anode chamber capacity is $500 \mathrm{ml}$, which specially designed for laboratory use. To control methanogen activity, headspace is taken about $6 \mathrm{~cm}$. Biodegradable plastic boxes were used for the anode chamber.

Rasayan J. Chem., 13(1), 672-675(2020)

http://dx.doi.org/10.31788/RJC.2020.1315556

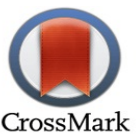




\section{RASĀYAN J. Chem.}

Vol. 13 | No. 1 |672-675| January - March | 2020

Unlike the anode chamber, cathode chamber is an aerobic chamber. It is also fabricated as same as the anode chamber with a capacity of $500 \mathrm{ml}$. It is attached to air spangler for external air supply. Aeration helps in accepting the electrons from the anode chamber and in turn, combines protons to form water. Proton Exchange Membrane, the agar-agar membrane is prepared using 3.5 gm of agar-agar powder in $100 \mathrm{ml}$ distilled water as shown in Fig.-1. Then the solution was first subjected to heat for blending and then poured into the PVC pipe and kept for some time till the membranes solidify.

\section{Experiments}

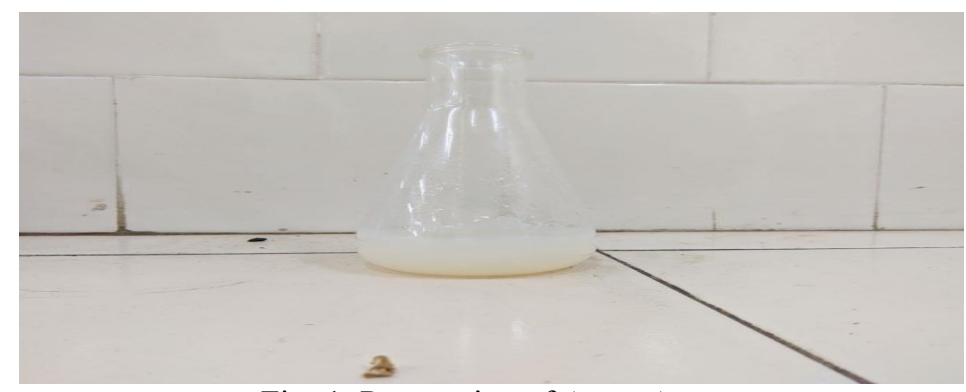

Fig.-1: Preparation of Agar- Agar

The main objective of these experiments is to find cost-effective and at the same time producing reasonable power density. Three laboratory setups were designed to compare power densities of three MFCs with different electrode materials; the volume of each MFC is $500 \mathrm{ml}$ and the dimensions of the electrodes are $6.35 \times 3 \times 0.2 \mathrm{~cm}$. MFC-I is fabricated with iron electrodes as shown in Fig.-2, MFC-II is fabricated with copper electrodes as shown in Fig.-3, and MFC-III is fabricated with silver nanoparticles (SNP) coated copper electrodes as shown in Fig.-4. The wastewater is collected from Khan River, Indore and before experiment cow dung $(5 \%)$ is added to the water to increase the growth of micro-organisms in the water. Setup is designed in a biodegradable plastic box that is sealed with the help of M-seal. Experiments are conducted for seven consecutive days.

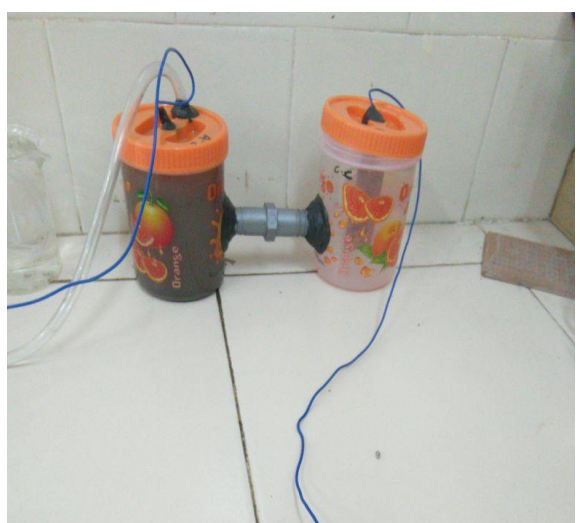

Fig.- 2: MFC- I

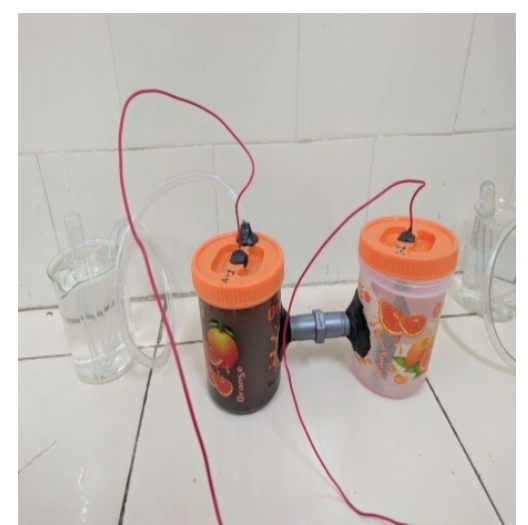

Fig.- 3: MFC- II

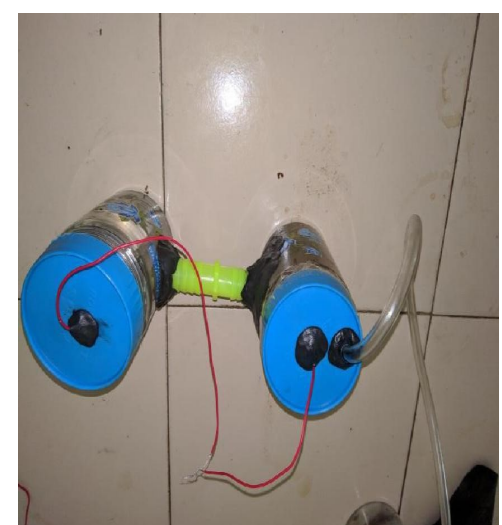

Fig.- 4: MFC-III

\section{RESULTS AND DISCUSSION}

\section{Evaluation of Electricity Generation}

Experiments were conducted and current and voltage readings were taken note daily for seven hours, successively for seven days using multi-meter. After taking the current and voltage readings power calculated using electrical power equation:

$$
\mathrm{P}=\mathrm{V} \times \mathrm{I}
$$

\section{Comparison of Power Densities of MFC-I, MFC-II and, MFC-III}

Power densities of all the MFCs compared here. And from Fig.-5 we come to know that the power density of copper electrode is higher than compared to the other two electrodes and iron has the lowest power density. So, for electricity generation, the copper electrode is a better option than others. 
RASĀYAN J. Chem.

Vol. 13 | No. 1 |672 - 675| January - March | 2020

Table -1: Khan River Wastewater Sample Primary Analysis

\begin{tabular}{c|c|c}
\hline Parameter & Kahn River Water & Kahn River Water +Cow Dung \\
\hline $\mathrm{pH}$ & 7.8 & 8.3 \\
\hline TDS (in ppm) & 650 & 913 \\
\hline Turbidity (NTU) & 22 & 49 \\
\hline BOD $(\mathrm{mg} / \mathrm{L})$ & 29.2 & 32.1 \\
\hline DO $(\mathrm{mg} / \mathrm{L})$ & 2.9 & 1.2 \\
\hline
\end{tabular}

Table -2: Readings for Comparison of the Power Density of MFC I, MFC II, and MFC III

\begin{tabular}{c|c|c|c}
\hline $\begin{array}{c}\text { Time } \\
\text { Days })\end{array}$ & $\begin{array}{c}\text { Power Density (micro } \\
\left.\text { Watt } / \mathrm{cm}^{2}\right) \text { MFC I }\end{array}$ & $\begin{array}{c}\text { Power Density (micro } \\
\left.\text { Watt/cm }{ }^{2}\right) \text { MFC II }\end{array}$ & $\begin{array}{c}\text { Power Density (micro } \\
\left.\text { Watt } / \mathrm{cm}^{2}\right) \text { MFC III }\end{array}$ \\
\hline 1 & 0.00572 & 0.01466 & 0.073302 \\
\hline 2 & 0.084755 & 0.325736 & 0.099645 \\
\hline 3 & 0.104455 & 0.440958 & 0.236882 \\
\hline 4 & 0.018326 & 0.487458 & 0.318864 \\
\hline 5 & 0.010079 & 0.491582 & 0.323216 \\
\hline 6 & 0.001833 & 0.431795 & 0.350475 \\
\hline 7 & 0.000687 & 0.394915 & 0.372924 \\
\hline
\end{tabular}

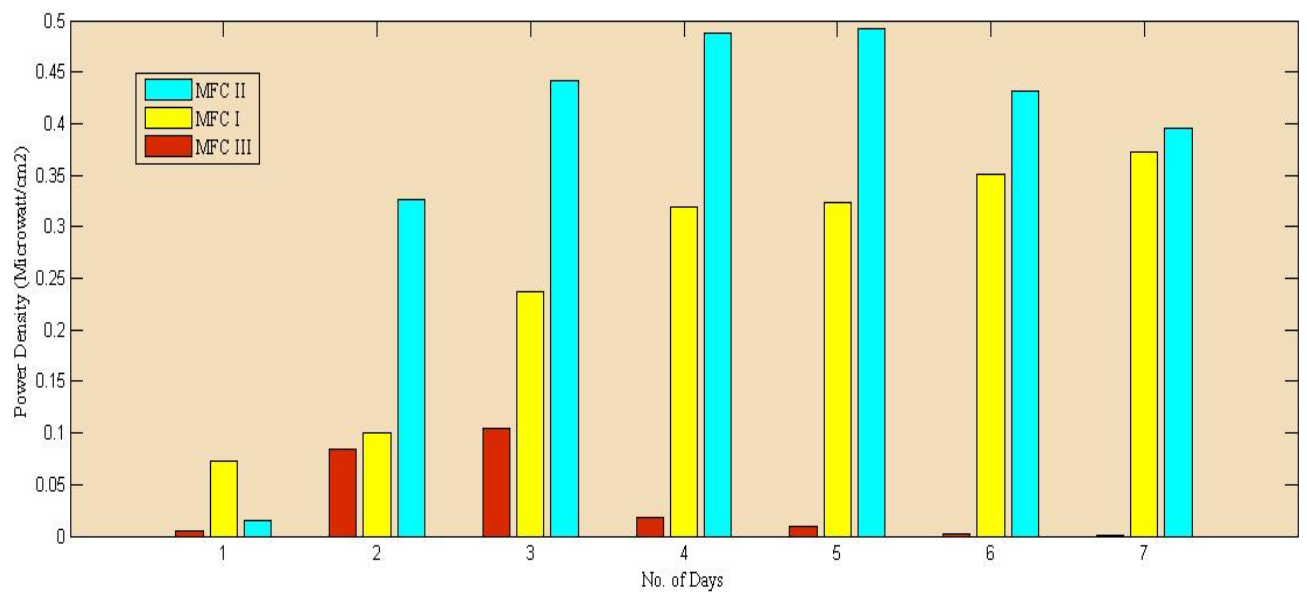

Fig.-5: Graphical Representation of Power Densities

\section{CONCLUSION}

Upon testing these three setups i.e. iron plates, copper plates and silver nanoparticles coated copper plates, the best performance was observed by copper plates. Maximum current and voltage observed for different setups are Iron- 30 micro Ampere and 0.8 Volt, Copper- 12 micro Ampere and 0.4 Volt and Silver Nanoparticle coated copper-32 micro Ampere and 0.5 Volt. And also the power density of the copper electrode is higher than the other two. The highest value of power densities of copper, SNP coated copper and Iron electrodes are 49.158172, 37.2924064 and $10.4455389 \mu \mathrm{W} / \mathrm{mm}^{2}$, respectively. Despite having great antibacterial properties, SNP has less power density when compared to copper and significantly more when compared to iron. If we use MFC for wastewater treatment and electricity generation, and our major focus is on electricity, then SNP is not economically feasible; Copper plates perform significantly better and are cheaper.

\section{REFERENCES}

1. M. Rahimnejad, A. Adhami, S. Darvari, A. Zirepour ,and Oh Sang-Eun, A review, Alexandria Engineering Journal, 54(3),745(2015), DOI:10.1016/j.aej.2015.03.031

2. A.Parkash, ,Journal of Applied and Emerging Sciences, 6(2) (2017)

3. E.Dannys, T. Green, A.Wettlaufer, Chandra Mouli R Madhurnathakam and A. Elkamel, , Journal of Bioprocessing \& Bio techniques 6, 267(2016) 
RASĀYAN J. Chem.

Vol. 13 | No. 1 |672 - 675| January - March | 2020

4. M. Zhou and Tingyue Gu, Journal of Microbial \& Biochemical Technology. Special issue, 1-4 (2013), DOI:10.1080/09593330.2013.813951

5. J. Liu, Y. Feng Liu, C. Feng, A.Wang, T. Tong Jia, L. Gongand and X. Likun, Energy Science \& Engineering 5, 217(2017)

6. A.Junyeong, H Jeon, J Lee, IS Chang, Environmental Science Technolology,15, 45(12),5441 (2011), DOI: $10.1021 / \mathrm{es} 2000326$.

7. M. Pandima Dev, International Journal of Pharma and Bio Sciences, 7(4), 38(2016)

8. M. Ramya, E. Senthilkumar, G. Sivagaami Sundari, K. Thileep Kumar, R. A. Kalaivani1, S. Raghu, and A.M.Shanmugaraj, Rasayan Journal of Chemistry, 12(1), 91(2019) DOI: 10.31788/RJC.2019.1215071

9. J. Singh, A. Jangra, Jai Kumar, Keerti Rani, and Ramesh Kumar, Rasayan Journal of Chemistry, 13(1), 105(2020), DOI: 10.31788/RJC.2020.1315382

10. S. Mulijani, G. Syahbirin1, and A.Wulanawati, Rasayan Journal of Chemistry, 11(1), 151(2018) DOI: $10.7324 /$ RJC.2018.111193.

[RJC-5556/2019] 